\title{
Effect of educational program on premenstrual syndrome in adolescent school girls
}

\author{
Ramya S, Rupavani K*, Bupathy A
}

\begin{abstract}
Department of Obstetrics \& Gynecology, Sri Manakula Vinayagar Medical College and Hospital, Madagadipet,
\end{abstract} Pondicherry - 605107, India

Received: 20 January 2014

Accepted: 2 February 2014

\section{*Correspondence:}

Dr. Rupavani K,

E-mail: obgrupa@gmail.com

(C) 2014 Ramya $\mathrm{S}$ et al. This is an open-access article distributed under the terms of the Creative Commons Attribution Non-Commercial License, which permits unrestricted non-commercial use, distribution, and reproduction in any medium, provided the original work is properly cited.

\begin{abstract}
Background: Premenstrual syndrome is a difficult problem in adolescence as the psychological changes that occur during the adolescent period are often complex and stressful. In this study, we aimed to study the prevalence and severity of premenstrual symptoms in adolescent girls and how effective an educational program is in decreasing the symptom severity in these girls.

Methods: An educational program was conducted in two rural and two urban secondary schools of Pondicherry in girls suffering from premenstrual symptoms. We assessed the symptom severity before conducting the educational program (pre-test) and three months following the program (post-test) by using a self-administered semi structured questionnaire.

Results: $40.9 \%$ of the urban girls and $51.6 \%$ of the rural girls were suffering from premenstrual symptoms. We noted a significant decrease in the total PMS scores and all the subscale scores (PMS - A, C, D, H and others) of the students three months after the educational program when compared to the scores before the program.

Conclusions: Women with PMS commonly present to their doctor with a self-diagnosis, only when the symptoms severely hamper their day to day activities. We suggest that health education programs regarding PMS and other menstrual problems must be included in the curriculum of secondary schools to bring down the prevalence of such problems.
\end{abstract}

Keywords: Premenstrual symptoms, Adolescent girls, Education

\section{INTRODUCTION}

Premenstrual syndrome (PMS) occurs 7-14 days before the onset of menstruation and subsides with the commencement of menstrual flow. It is associated with physical, psychological and behavioural changes. ${ }^{1}$ PMS can affect menstruating women of any age and the effect is different for each woman. ${ }^{2}$ This is a difficult problem in adolescence as the psychological changes that are occurring during this time of a woman's life are often complex and stressful. ${ }^{3} \mathrm{~A}$ wide range of symptoms have been described, but it is their timing and severity that are most important. Depression, irritability, anxiety, tension, aggression, inability to cope and feeling out of control are the typical psychological symptoms. Bloatedness, mastalgia and headache are classical physical symptoms. ${ }^{4}$ In a study done by Zibataghizadeh et al in adolescent girls, $28.89 \%$ of the girls had severe PMS. ${ }^{5}$ Even though the etiology of PMS is still unknown; several treatment modalities have been shown to be effective. ${ }^{6}$ In this study, we aimed to study the prevalence of premenstrual symptoms in adolescent girls and its severity and the effect of educational program in adolescents suffering from premenstrual symptoms. 


\section{METHODS}

Letters were sent to four secondary schools (2 urban and 2 rural) located in Pondicherry, to ask for the participation of their students in a research study on adolescent girls' health after getting ethical committee approval. A short discussion between the school teachers and the researcher was held to provide further explanations of the study rationale and procedures. It was an interventional study. Students of 8th, 9th and 10th grades who have given consent to participate in the study were given a preliminary questionnaire regarding their menstrual cycles. Girls who have not attained menarche, those who had irregular menstrual cycles, those who were suffering from chronic diseases and girls who were taking hormonal therapy or anti-depressants were excluded from the study. All the students who reported to have premenstrual symptoms were invited for an educational program.

The program included the following contents: the physiology of menstruation, defining premenstrual symptoms and prevalence of premenstrual symptoms among adolescents and why premenstrual symptoms occur. They were provided information on different categories of PMS symptoms and their impact on various aspects of life. The relation between stress and premenstrual symptoms and various self-help measures to manage stress including learning to deal with one's own emotional symptoms, scheduling activities, using Menstrual Symptom Diary were discussed. Various selfcare measures related to dietary change and the importance of physical activities in combating premenstrual symptoms were discussed. After the program was completed, the students were given multiple choice questions regarding the aspects discussed. The students who scored less than $50 \%$ were given a repeat session next day.

Immediately after the program, the students were given a detailed self-administered questionnaire which included demographic data, socio-economic data and premenstrual symptoms and the degree of severity of the symptoms they experienced. Premenstrual symptoms were divided into 5 subgroups: PMS-A for behavioral changes, PMS-H indicating water and salt retention, PMS-C manifestations of craving, and PMS-D characterizing depression and other PMS symptoms. Each symptom was scored as 1, 2 \& 3 depending on the severity of the symptom and the scores in each sub group were added. The students were given premenstrual symptom dairy and were asked to mark their symptoms at the end of each day. Three months after the educational program, students were given premenstrual symptom questionnaire again and the differences in the prevalence and severity of premenstrual symptoms before and after the educational program were studied by comparing the pre-test and post test scores in each sub group Statistical analysis was done using SPSS V19 software. Mean was analysed for age, BMI and age of menarche. Pre-test and post-test results were compared using Wilcoxon test.

\section{RESULTS}

Out of the 711 students in urban schools who answered the preliminary questionnaire on menstrual abnormalities, $291(40.9 \%)$ reported to have premenstrual symptoms. In rural schools, out of 244 students who answered the questionnaire, $126(51.6 \%)$ reported to have premenstrual symptoms. The demographic variables like the mean age, mean age of menarche, and the mean BMI of the students are shown in Table 1.

Table 1: Demographic variables of the students.

\begin{tabular}{|lll|}
\hline & Rural & Urban \\
\hline Age & $14.33 \pm 0.95$ & $13.7 \pm 1.104$ \\
\hline Age of menarche & $12.81 \pm 1.025$ & $11.96 \pm 0.918$ \\
\hline BMI & $17.38 \pm 2.094$ & $19.17 \pm 0.918$ \\
\hline
\end{tabular}

Table 2 shows the scores of the students in the test conducted to assess the knowledge of the students after the first educational session. 62 rural students and 77 urban students scored $<50 \%$ in the test and required a repeat session the next day.

Table 2: Premenstrual syndrome knowledge questionnaire results.

\begin{tabular}{|lll|}
\hline PMS KQ scores & Rural & Urban \\
\hline $0-50 \%$ & 62 & 77 \\
\hline $60-100 \%$ & 64 & 214 \\
\hline
\end{tabular}

Table $3 \& 4$ show the difference in the severity of each subgroup of premenstrual symptoms and total premenstrual symptoms before the educational intervention (pre-test) and 3 months after the intervention (post-test) in rural \& urban schools respectively.

Table 3: Comparison of pretest and post test scores in rural students.

\begin{tabular}{|lllll|}
\hline \multirow{2}{*}{ Rural } & & Mean \pm SD & Z & $\begin{array}{l}\text { P } \\
\text { value }\end{array}$ \\
\hline \multirow{2}{*}{ PMS-A } & Pre-test & $2.29 \pm 2.01$ & -5.670 & 0.000 \\
\cline { 2 - 3 } & Post-test & $1.13 \pm 1.54$ & & \\
\hline \multirow{2}{*}{ PMS-C } & Pre-test & $4.88 \pm 3.09$ & -8.677 & 0.000 \\
\cline { 2 - 3 } & Post-test & $1.21 \pm 1.44$ & & \\
\hline \multirow{2}{*}{ PMS-D } & Pre-test & $1.02 \pm 1.25$ & -3.148 & 0.002 \\
\cline { 2 - 3 } & Post-test & $0.59 \pm 0.87$ & & \\
\hline \multirow{2}{*}{ PMS-H } & Pre-test & $1.79 \pm 2.12$ & -5.622 & 0.000 \\
\cline { 2 - 3 } PMS-Others & Post-test & $0.6 \pm 1.12$ & -6.343 & 0.000 \\
\cline { 2 - 3 } & Pre-test & Post-test & $1.99 \pm 3.27$ & \\
\hline \multirow{2}{*}{ PMS-Total } & Pre-test & $13.99 \pm 8.09$ & -8.963 & 0.000 \\
\cline { 2 - 3 } & Post-test & $5.37 \pm 4.94$ & & \\
\hline
\end{tabular}


Table 4: Comparison of pretest and post test scores in urban students.

\begin{tabular}{|c|c|c|c|c|}
\hline Urban & & Mean \pm SD & $\mathbf{Z}$ & $\begin{array}{l}P \\
\text { value }\end{array}$ \\
\hline \multirow{2}{*}{ PMS-A } & Pre-test & $2.43 \pm 2.49$ & \multirow{2}{*}{-8.985} & \multirow{2}{*}{0.000} \\
\hline & Post-test & $0.80 \pm 1.25$ & & \\
\hline \multirow{2}{*}{ PMS-C } & Pre-test & $1.93 \pm 2.14$ & \multirow{2}{*}{-6.472} & \multirow{2}{*}{0.000} \\
\hline & Post-test & $0.91 \pm 1.48$ & & \\
\hline \multirow{2}{*}{ PMS-D } & Pre-test & $1.98 \pm 2.49$ & \multirow{2}{*}{-8.522} & \multirow{2}{*}{0.000} \\
\hline & Post-test & $0.52 \pm 1.09$ & & \\
\hline \multirow{2}{*}{ PMS-H } & Pre-test & $1.02 \pm 1.06$ & \multirow{2}{*}{-4.487} & \multirow{2}{*}{0.000} \\
\hline & Post-test & $0.57 \pm 1.20$ & & \\
\hline \multirow{2}{*}{ PMS-Others } & Pre-test & $2.47 \pm 2.49$ & \multirow{2}{*}{-5.780} & \multirow{2}{*}{0.000} \\
\hline & Post-test & $1.38 \pm 1.91$ & & \\
\hline \multirow{2}{*}{ PMS-Total } & Pre-test & $9.84 \pm 7.97$ & \multirow{2}{*}{-9.310} & \multirow{2}{*}{0.000} \\
\hline & Post-test & $4.13 \pm 4.93$ & & \\
\hline
\end{tabular}

The total PMS scores and all the subscale scores of the rural students showed significant difference between pretest and post-test with: total PMS scores $(Z=-8.963, P=$ 0.000), PMS-A subscale scores $(Z=-5.670, P=0.000)$, PMS-C subscale scores $(Z=-8.677, P=0.000)$, PMS-D subscale scores $(Z=-3.148, P=0.002)$ and PMS-H subscale scores $(Z=-5.622, P=0.000)$, and other PMS symptoms $(Z=-6.343, P=0.000)$ that indicated a decrease in PMS symptom severity among these variables. Similarly, even in urban students, the total PMS scores and all the subscale scores showed highly significant difference between pre-test and post-test with: total PMS scores $(Z=-9.310, P=0.000)$, PMS-A subscale scores $(Z=-8.985, P=0.000)$, PMS-C subscale scores $(Z=-6.472, P=0.000)$, PMS-D subscale scores $(\mathrm{Z}=-8.522, P=0.000)$ and PMS-H subscale scores $(Z=$ $-4.487, P=0.000)$, other PMS symptoms $(\mathrm{Z}=-5.780, P$ $=0.000)$ that indicated a decrease in premenstrual symptom severity among these variables. In fact, out of the total students who reported premenstrual symptoms before the educational intervention, 38 (30.2\%) rural students and $100(34.4 \%)$ urban students did not have any PMS symptom in the post-test.

\section{DISCUSSION}

Many studies were performed to study the prevalence of PMS in the adolescent age group in India. Amita Singh et al. ${ }^{9}$ studied prevalence of PMS in medical students in Rewa, Madhya Pradesh in 2008 and found that $60.5 \%$ of the students suffered from PMS. Tamil Selvi ${ }^{10}$ et al. in Cuddalore, Tamilnadu found a prevalence of $55.3 \%$. Dr. Dharmpal G. Dambhare et al. ${ }^{11}$ found a prevalence of $56.16 \%$ PMS in Maharashtra. Even in our study, the prevalence of PMS was found to be $40.9 \%$ in urban school girls and $51.6 \%$ in rural school girls. These results are almost comparable to the above studies.

The pathogenesis of PMS is almost certainly more complex than the combination of ovarian activity and the resulting neurotransmitter changes. P M S O Brien et al. ${ }^{12}$ suggested that many other factors may have a role, including environmental, psychological and personal factors. Hence, it is not surprising that women respond to non-specific measures like dietary changes, self-help, exercise, stress management and relaxation exercises. In our study, we tried to evaluate the effect of health education regarding these non-specific measures in managing premenstrual symptoms. To the best of our knowledge, this study is the first of its kind in India.

We found a highly significant improvement in the severity of each subgroup of premenstrual symptoms (PMS - A, C, H, D \& Others) and total PMS as such in our study. Even the prevalence of PMS has decreased significantly. These results are comparable to the study done by Janitha P. Chau et al. ${ }^{1}$ who studied the efficacy of educational program in increasing the knowledge and decreasing the severity of symptoms of PMS among secondary school going students in Hong Kong and found that there is significant improvement in PMS symptoms in the study group when compared to the control group. Our study definitely proves that educating students regarding the causes of PMS symptoms, encouraging them to maintain a PMS symptom dairy, and advising some minor changes in their dietary pattern during the premenstrual phase and daily physical activity will be definitely useful in combating PMS.

Hence, we suggest that health education programs regarding PMS and other menstrual problems must be included in the curriculum of secondary schools to bring down the prevalence of such problems.

\section{ACKNOWLEDGEMENTS}

The authors wish to acknowledge that the study was done as part of the Indian Council of Medical Research 'Short Term Studentship' programme.

\section{Funding: ICMR STS funding}

Conflict of interest: None declared

Ethical approval: The study was approved by the institutional ethics committee

\section{REFERENCES}

1. Chau JPC, Chang AM. Effects of an educational programme on adolescents with premenstrual syndrome. Health Education Research. 1999;14(6):817-30.

2. Ray S, Mishra SK, Roy AG, Das BM.. Menstrual characteristics: a study of the adolescents of rural and urban West Bengal, India. Ann Hum Biol. 2010;37(5):668-s81.

3. O'Brien. Premenstrual syndrome. In: Keith Edmonds D, eds. Dewhurst' Text book of Obstetrics and Gynaecology. 7th ed. USA: Blackwell publishing; 2007: 408-413.

4. Keith Edmonds D. Premenstrual syndrome. In: Keith Edmonds D eds. Dewhurst' Text book of Obstetrics 
and Gynaecology. 7th ed. USA: Blackwell publishing; 2007: 408-413.

5. Taghizadeh Z, Shirmohammadi M, Arbabi M, Mehran A. The Effect of Premenstrual Syndrome on Quality of Life in Adolescent Girls. Iran J Psychiatry. 2008;3:105-9.

6. Halbreich U, Borenstein J, Pearlstein T, Kahn LS. The prevalence, impairment, impact, and burden of premenstrual dysphoric disorder (PMS/PMDD). Psychoneuroendocrinology. 2003;28(Suppl 3):1-23.

7. Bakhshani NM, Mousavi MN, Khodabandeh G. Prevalence and severity of premenstrual symptoms among Iranian female university students. J Pak Med Assoc. 2009;59(4):205-8.

8. Tabassum S, Afridi B, Aman Z, Tabassum W, Durrani R. Premenstrual syndrome: frequency and severity in young college girls. J Pak Med Assoc. 2005;55(12):546-9.

9. Amita Singh, Dukhu Kiran, Harminder Singh, Bithika Nel, Prabhakar Singh, Pavan Tiwari.
Prevalence and severity of dysmenorrhea: a problem related to menstruation, among first and second year female medical students. Indian J Physiol Pharmacol. 2008;52(4):389-97.

10. K. Tamilselvi. Premenstrual Syndrome of Adolescent Girls in Cuddalore District, Tamil Nadu, India. International Journal of Social Science Tomorrow. 2012;1(7):1-6.

11. Dharampal G. Dambhare, Sanjay V. Wagh, Jayesh Y. Dudhe. Age at Menarche and Menstrual Cycle Pattern among School Adolescent Girls in Central India. Global Journal of Health Science. 2012;4(1):105-11.

12. O'Brien PM. Helping women with premenstrual syndrome. BMJ. 1993 Dec;307(6917):1471-5.

DOI: $10.5455 / 2320-1770 . i j r \operatorname{cog} 20140333$

Cite this article as: Ramya S, Rupavani K, Bupathy A. Effect of educational program on premenstrual syndrome in adolescent school girls. Int J Reprod Contracept Obstet Gynecol 2014;3:168-71. 